\title{
A FRENTE PERFORMÁTICA DE ATUAÇÃO DO DRAMATURGO NA CENA CONTEMPORÂNEA
}

Resumo

Este artigo analisa a aproximação dos campos da dramaturgia e da performance, mobilizando apontamentos em torno dos territórios e das fronteiras de suas bases epistemológicas e processuais. A discussão teórica parte de Richard Schechner, Erika Fischer-Lichte, Renato Cohen, Denise Pedron e Ana Pais, com foco na investigação sobre como os desdobramentos dos princípios da performance contaminam o pensamento e a práxis da escrita para o palco. Nessa perspectiva, discute-se o redimensionamento do trabalho do dramaturgo e seu papel simbólico na gênese criativa, principalmente quando sua atuação incorpora uma frente performática e a dramaturgia passa a ser entendida como campo expandido.

Palavras-chave:

Dramaturgia; Performance; Campo Expandido. 


\section{A FRENTE PERFORMÁTICA DE ATUAÇÃO DO DRAMATURGO NA CENA CONTEMPORÂNEA}

$\overline{\text { Eder Rodrigues - Doutor }}$ pela Universidade Federal de Minas Gerais com tese sobre a dramaturgia contemporânea. Mestre pela Universidade Federal de Minas Gerais. Dramaturgo, encenador e pesquisador. Professor de artes cênicas.

ederdelrodrigues.literatura@ gmail.com.

\section{Eder Rodriques (UFMG)}

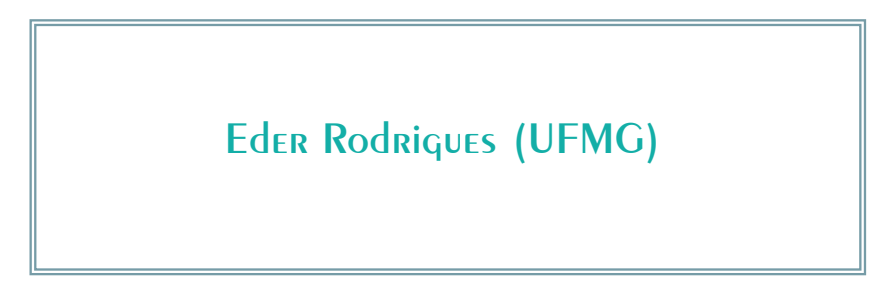

A abrangência do termo dramaturgia atualmente pode ser lida como o resultado do percurso de transformações pelo qual passou o texto teatral ao longo dos séculos, somado à dinamicidade com que, historicamente, o exercício e o pensamento dramatúrgicos foram construídos. A pluralidade que o entendimento do termo adquiriu nesse percurso imprime um outro olhar sobre a prática atual, principalmente junto ao ofício do dramaturgo que enfrenta sensíveis mudanças na sua gênese laboral e no redimensionamento do valor simbólico que exerce no âmbito da criação.

Nas últimas décadas do século XX, a criação teatral esteve permeada muito mais pelos meandros dos processos do que pelos seus produtos, e é na atenção devida a essa processualidade que alimentamos esta abordagem crítica sobre a atuação performática do dramaturgo. Essa discussão teórica provoca uma abordagem plural sobre dois vetores: o texto em relação às fontes tradicionais de produção e o caráter coletivo de sua gênese, modulações que sedimentam o campo expandido das 
práticas dramatúrgicas expressas no repertório contemporâneo.

Dentro dessa perspectiva, torna-se possível reconhecer a pluralidade conceitual do termo dramaturgia, confrontando e tensionando o modus operandi de seu profissional responsável. Nesse confronto, reconhecemos algumas linhas de força capazes de aproximar o campo de atuação do dramaturgo aos conceitos (ideológico, processual e de fronteira) em torno do papel do performer, apontando para um percurso em que a própria dramaturgia se transforma no objeto da experiência teatral. Essas linhas de força tensionam campos que assinalamos como próximos (dramaturgia e performance) e que percebemos como instrumentos propositivos para tecer reflexões baseadas no contato dessas práticas.

A partir do cotejo das convergências desses dois campos e seus desdobramentos, torna-se possível redimensionar a esfera do trabalho dramatúrgico na cena emergente, em especial quando se trabalha com as tensões entre o visível e o invisível da materialidade dramatúrgica, a identidade e a alteridade de suas formas, o caráter coletivo e o viés relacional de sua experiência.

A performance enquanto modalidade artística e corpus teórico-reflexivo de práticas divergentes tem, nos anos 60 e 70 do século passado, destacada importância, principalmente no que refere a uma práxis em que o diálogo interartes, o prospecto de rupturas com os padrões das artes estabelecidas e o foco no lócus criativo acabam contaminando outros campos artísticos. A aproximação entre dramaturgia e performance se torna relevante na medida em que seus processos de criação caminham para esferas contextuais, metodológicas e paradigmáticas capazes de sinalizar pontos de contato entre seus pressupostos. Esse contato também mobiliza a construção de outros espaços de subjetivação, motor que possibilita pensar a dramaturgia como conceito vinculado à uma prática naturalmente plural, e, também, enquanto campo expandido.

As teorizações envolvendo a performance em seus desdobramentos artísticos e enquanto ferramenta de análise englobam um contexto que pressupõe a subversão dos padrões estéticos vigentes (principalmente aqueles tidos como convencionais e hegemônicos), a viabilidade do convívio de distintas artes (a partir da inclusão de novos elementos tecnológicos, contextuais e ideológicos) e a instauração de um terreno baseado no âmbito experimental. $O$ surgimento da performance pode ser entendido como uma fissura no pensamento e na prática normativa do século $\mathrm{XX}$, que encontra na soma de vários paradigmas dissidentes uma corrente de ruptura nos mais diversos segmentos da arte.

A performance se apresenta de maneira mais abrangente, como manifestação artística e também como conceito, proporcionando uma reavaliação dos valores contidos nas práticas artísticas e culturais da sociedade. O centro de interesse do fenômeno, no século vinte, não reside mais na expressão individual ou numa preocupação conceitual, mas principalmente no fazer cultural. [...] A performance pode ser tomada como conceito amplo pelo qual transitam diversas manifestações artísticas, não só happenings ou ações, mas também o teatro, o cinema, a dança, a literatura, as artes visuais. (PEDRON, 2006, pp. 31-32)

Os desdobramentos da performance foram além do âmbito da modalidade artística que ela inaugura. $\mathrm{O}$ atravessamento de universos culturais distintos propulsiona uma nova práxis e, também, um campo teórico capaz de servir de chave para o entendimento de novos saberes, além dos dispositivos que os aportes provocam quando aproximamos a diversidade de seus meios operacionais à outros campos - nesse caso, com o da topografia do trabalho dramatúrgico. A natureza performática também se confronta com os prospectos doutrinários de visões e valorizações do mundo (seletivo e excludente), principalmente ao potencializar seu viés interrogativo, relativizador e dissidente.

O surgimento da performance gera impactos significativos no cenário artístico através da ruptura com os parâmetros institucionalizados, ou mesmo pela ratificação de caminhos estéticos (contrários e possíveis), com destacada presentificação política e ideológica, característica que outorga aos processos vivenciados um viés performativo. As novas formas de ver, 
de ler e de dialogar com o mundo começam a aparecer não só nas novas modalidades expressivas, mas também na processualidade que as engendra.

Um dos expoentes dos estudos sobre performance é Richard Schechner, fundador do The Performance Group of New York, em 1967, Grupo de Teatro Experimental, sendo o seu diretor artístico até 1980, e, também, um dos fundadores do Centro de Estudos da Performance, junto à New York University. Richard Schechner tornou-se uma referência em torno dos estudos da performance e suas adjacências. Porém, no começo de seu trabalho, foco referencial deste artigo, esteve ligado diretamente aos pressupostos performáticos junto aos projetos desempenhados como diretor de teatro.

O trabalho de Schechner como encenador na década de 1960 consistiu na busca por novos parâmetros de criação a partir de uma articulação entre a teoria, a prática e as tendências experimentais. Ao expandir as ressignificações do campo da performance para as outras artes, suas pesquisas sublinham o diagnóstico de uma cena modificada em relação aos dispositivos convencionais que regravam o status expressivo das linhas dramáticas em geral.

Em um primeiro momento de trabalho, Richard Schechner é radical no sentido de negar a utilidade do texto, já que, segundo Schechner (2012, p. 34) “o dramaturgo não estando presente na sala de ensaios, era uma espécie de proprietário ausente, distante". Essa ausência começa a ficar injustificável diante dos estudos potenciais da arte da presença e de uma cena sedenta por processos engendrados na sala de ensaio, espaço aberto às contaminações que os experimentos híbridos oriundos do campo da performance alimentavam na época. Em um segundo momento, há um recuo do diretor norte-americano, que relativiza seus pressupostos e passa a reconhecer a força do texto, procurando, inclusive, novas formas de elaborá-lo, ou de se trabalhar, de acordo com o próprio Schechner (2012, p.34), "radicalmente o modo de essas obras serem recebidas, experienciadas". O que se torna perceptível é o fato de que uma nova instância de trabalho dramatúrgico é fomentada ao alimentar a figura de um profissional presente, sensível e atento a essa presença, no caso, permeável às novas experiências e vínculos firmados no terreno criacional.

É possível perfilar nas raízes desse pensamento uma corrente propositiva para o ato de se testar os limites do texto e, também, de contrapor suas práticas hegemônicas. $\mathrm{O}$ trabalho com a contaminação entre as artes, em processos que agregam novas frentes metodológicas, também caracteriza o prosseguimento das pesquisas de Schechner ${ }^{1}$, cada vez mais marcadas pelo cruzamento das culturas, além do fato da presença do dramaturgo nos ensaios se apresentar como uma prerrogativa emergencial incontornável.

No Brasil, a aproximação entre dramaturgia e performance tem, no trabalho de Renato Cohen ${ }^{2}$, um pioneirismo determinante na difusão das ideias convergentes desse diálogo. $\mathrm{O}$ trabalho de Cohen parte exatamente do campo relacional entre teatro e performance, junto a uma investigação sobre como os processos criativos de ambos os campos tensionam mecanismos que se retroalimentam, gerando impacto, inclusive, nas formas de trabalho com o texto.

A aproximação do teatro e da performance procura mensurar como as duas linguagens se contaminam mutuamente, e ilumina pontos convergentes nos seus processos e interfaces. É na luz das dinâmicas dessa processualidade que surge uma cena na qual as fronteiras são diluídas, e, também, onde a desterritorialidade característica dessa convergência se mos-

\footnotetext{
${ }^{1}$ O trabalho de Richard Schechner segue na proposta de fortalecimento da Teoria da Performance como novo campo de estudo, concentrando-se nas diretrizes do "comportamento restaurado", que passa a ser um conceito central em seus estudos, dentro de um contexto mais complexo envolvendo a cultura e o performático.

${ }^{2}$ Renato Cohen iniciou suas pesquisas neste âmbito em 1983, após ter participado do curso de Luiz Galizia intitulado "Processos criativos de Robert Wilson". As influências de Bob Wilson e do professor e pesquisador Jacó Guinsburg são determinantes na difusão de seu trabalho. O confronto direto entre a performance e a instância teatral tem, no trabalho de Cohen, uma prática desbravadora com o intuito de potencializar estas discussões em solo brasileiro, além de ratificar um espaço teórico de discussão do tema, entendido por ele como um correspondente da práxis vivenciada.
} 
trou como um espaço apto à fusão dos gêneros e ao olhar escritural amplo e disjuntivo.

O pensamento de Cohen sublinha a força propulsora da performance nos processos criativos, principalmente quando reconhece um terreno fértil que se abre ao experimental como um espaço de investigação de linguagens, de diluição dos aparatos genéricos, além da descoberta de outros expedientes motores. Com a difusão da obra de Cohen, esse segmento experimental e alternativo que se difundiu no Brasil acaba alertando para ressignificações nas redes criativas no que tange à desierarquização dos módulos de trabalho, ao rompimento com a herança representativa e à reestruturação do corpus operacional de criação.

No âmbito dramatúrgico, suas considerações deslocam o pensamento em torno do texto para a topografia de sua práxis, sublinhando, no caso, que, na cena, a instância prática do trabalho dramatúrgico é que seria capaz de construir suas necessidades, diálogos e abrangências. Para Cohen:

A palavra "texto" deve ser entendida no seu sentido semiológico, isto é, como um conjunto de signos que podem ser simbólicos (verbais), icônicos (imagéticos) ou mesmo indiciais (sombras, ruídos, fumaças, figuras delineadas por luzes etc). (COHEN, 1989, p. 29)

Essa abordagem estabelece uma noção plural da gênese laboral, já que acrescenta à escrita dramatúrgica formas pertencentes a outros sistemas não restritos ao correspondente verbal. Essa fissura na prática processual de criação tem sua raiz na genealogia das ações performáticas, e passa a fazer parte do horizonte de perspectivas experimentais dos coletivos teatrais, que se enveredam pela égide das criações compartilhadas. Esse deslocamento gradual dos coletivos junto aos processos partilhados amplia o repertório instrumental do dramaturgo, redefinindo seu papel a partir de uma rede de conexões possíveis com todo o repertório que os ensaios podem nutrir. No caso de Cohen, não se trata apenas de uma especulação teórica, mas de compartilhar as potencialidades e intensidades que a processualidade de raiz performá- tica pode explorar, fazendo com que o exercício de repensar a própria prática contamine outras artes, no caso, o campo operacional dramatúrgico.

É nossa intenção apontar, através da observação de diversos espetáculos, a estrutura e, mais do que isso, a ideologia que está por trás da expressão artística performance, e ao mesmo tempo, com essa análise, enfocar todo um riquíssimo universo de criação ainda parcialmente desconhecido do grande público no Brasil. (COHEN, 1989, p. 50)

A fronteira entre o viés performático de criação e o trabalho textual junto aos coletivos reelabora o olhar do dramaturgo a partir da utilização dos múltiplos elementos cênicos e, também, daqueles que assim se transformam através da vivência nos ensaios e de um enfoque que, segundo Cohen $(1989$, p. 66) recai sobre a "forma de construção, que privilegia a forma, a estrutura, em detrimento do conteúdo e da linha narrativa".

Essa forma de construção dramatúrgica questiona as expectativas temáticas e dramáticas, mobilizando um terreno em que a tessitura e suas conexões passam a ser extraídas das tensões e das retroalimentações provenientes dos encontros entre os agentes criadores. Expedientes com esse viés também movimentam um estatuto diferenciado de se compor, provocando uma abordagem polissêmica do corpus dramatúrgico, ou, de acordo com o próprio Cohen (1989, p.74), "com o texto funcionando como matriz de um conjunto de possibilidades."

Um fator determinante no pensamento de Renato Cohen (1989) a ser destacado junto a essas questões é o deslocamento que provoca ao inferir que, na performance, a intenção se desloca do what para o how (do que para o como), rompendo, conforme enfatizado por Cohen (1989, p.66), "com o discurso narrativo, a história passa a não interessar tanto, e sim como aquilo está sendo feito". Essa colocação se desdobra no momento em que esse "como" passa a ser o foco das investigações, experimentações e pesquisas. No caso, o correspondente direto desse "como" passa pela dramaturgia, já que o material criado nos ensaios e as propostas artís- 
ticas colocadas são efetivados nesse âmbito.

Estendendo essa aplicabilidade para o terreno do performático, o qual assinalamos como força motriz capaz de agregar instâncias de trabalho convergentes, Cohen chega inclusive a esclarecer pontos para essa discussão, referindo-se ao performer dentro dessa nova perspectiva:

O performer trabalha em cima de suas habilidades, sejam elas simplesmente físicas [...] ou totalmente intelectuais. [...] O performer vai desenvolver e mostrar suas habilidades pessoais, sua idiossincrasia. É a criação de um vocabulário próprio. [...] O que interessa é uma marca pessoal ou uma marca de grupo, em caso de mais pessoas. É a definição de um estilo, de uma linguagem própria. (COHEN, 1989, p. 102-103)

Nesse mesmo segmento teórico, o trabalho da pesquisadora e dramaturga Denise Pedron enfatiza as relações intrínsecas entre a performance e a escrita ${ }^{3}$, apontando os aspectos performativos de determinados textos quando lidos a partir dos princípios operacionais performáticos. Pedron demonstra como esses princípios performáticos elaboram novas expectativas de construção textual que confrontam o status ou a fixidez de sua natureza convencional. Esses princípios nos orientam a pensar textos teatrais que são construídos a partir de uma fonte heterogênea de elementos, confrontando o estatuto do texto dramático (pertencente à tradição) com o do texto espetacular (construído segundo as exigências do palco). A ideia parte de um entendimento do texto como percurso.

O texto representa o todo da encenação incluindo elementos verbais - as falas e possíveis diálogos - e não verbais - a música, a iluminação, o espaço, a atmosfera. Muitas vezes, o texto tem sua notação feita sob a forma de um roteiro que indica alguns caminhos a serem percorridos sem, no entanto, fixar as situações a serem vivenciadas, pois a performance ressalta-se como uma identidade em permanente construção, um organismo vivo e pulsante disposto à constante mudança.
(PEDRON, 2006, p. 69)

A pesquisa de Denise Pedron determina alguns operadores para essa articulação teórica entre a performance e as textualidades decorrentes de seus pressupostos, como: o caráter político, o performer, o espectador como participante, a corporeidade, o tempo-duração e o texto da performance. A pesquisadora utiliza esses operadores para definir o texto como performático, a partir de critérios como o reconhecimento do escritor de seu local de enunciação (evidenciando-o, ao invés de disfarçá-lo com as técnicas ficcionais implícitas ou explícitas), a corporeidade (como veículo, instrumento e objeto da escrita), além de outras relações entre o texto e o leitor capazes de ultrapassar a fronteira das letras.

Dos operadores que Pedron articula, o do "performer" é o que se liga diretamente às questões que este artigo discute. No desenvolvimento desse tópico, os estudos da pesquisadora partem de uma pergunta que alimenta a principal questão suscitada nessa reflexão: "E quando o autor ocupa um lugar equivalente ao do performer?" (PEDRON, 2006, p. 73). A pergunta formulada instaura o ponto nevrálgico desse debate, principalmente quando ampliamos essa interrogação para o campo da dramaturgia: e quando o dramaturgo ocupa um lugar equivalente ao do performer, expondo uma zona de colisão entre os campos dramatúrgicos e performáticos como instância instauradora de novas tensões, pensamentos e ressignificações do seu modo de trabalho?

Ao investigar o campo da performance como conceito e expandi-lo para se pensar suas ressonâncias em outras linguagens, abre-se margem para que o diálogo entre os princípios que norteiam os parâmetros performáticos possa ser articulado com a vivência dos processos dramatúrgicos. Nesse sentido, o campo da dramaturgia, quando examinado a partir desse viés performático, apresenta um espaço redimensionado em que o caráter polissêmico dos seus

\footnotetext{
3 A tese de doutorado de Denise Pedron intitulada "Um olhar sobre a performatividade na cultura contemporânea: a performance como conceito e a produção artística de Diamela Eltit" (2006), traça um percurso conceitual sobre a performance em diálogo com o universo da escrita.
} 
registros, resultante tanto nas obras como nos processos laborais, sublinha o descentramento característico dos territórios e das fronteiras do ofício. Esse reconhecimento do processo criativo como mobilizador de conceitos, significados e ideologias instaura uma possibilidade teórica instigante: permear a experiência dramatúrgica como uma definição performática do percurso escritural que ela promove. Nesse caso, passa-se a reconhecer as instâncias que o dramaturgo imprime em seu trabalho, bem como o posicionamento político-ideológico do coletivo com quem partilha o labor (e no qual o seu próprio também se agrega) como traços identitários do trabalho, além de endossar o fato de que esses posicionamentos passam também a fazer parte dos paradigmas estéticos e da estrutura dramatúrgica encontrada para organizar o espetáculo como um todo.

Se a atuação do dramaturgo passa a exercer esse papel, ainda que provisório, na gênese criativa, podemos estender o termo performer junto à sua funcionalidade e ampliar o entendimento da dramaturgia como um espaço de experiência. Seguindo esse princípio, a dramaturga e pesquisadora Ana Pais, uma das principais teóricas da cena contemporânea de Portugal que se dedica às questões envolvendo as fronteiras do trabalho dramatúrgico junto às artes performativas, elenca processos em que a performance desencadeia uma influência determinante sobre os dispositivos dramatúrgicos, deslocando funcionalidades, antes tidas como mais ou menos fixas, para um terreno plural e próprio da cena.

A performance abre um universo de questionamento e reflexividade que exige um trabalho dramatúrgico na estruturação dos sentidos do espetáculo e uma procura de outras lógicas de organização dos materiais, deixando as suas marcas bem visíveis na diversidade das práticas contemporâneas. (PAIS, 2010, p. 80)
Os apontamentos de Ana Pais subsidiam o pensamento recente sobre poéticas dramatúrgicas que dialogam com o pensamento sobre a figura de um articulador textual, que atravessa campos distintos para permear instâncias performativas. Essa perspectiva faz parte da linha de pensamento que mobilizamos ao problematizar questões sobre como o dramaturgo pode atuar enquanto performer em determinadas instâncias de trabalho, tanto articulando os campos da linguagem e da estética impressa no trabalho, quanto imprimindo sua inserção política e ideológica. Essa premissa só é possível quando voltamos nosso olhar para as práticas atuais e, de fato, inserimos o entendimento da dramaturgia como um espaço de experiência.

A dramaturgia, a partir da segunda metade do século XX, tem, na fenomenologia dos seus processos e na sua efetivação enquanto espetáculo, o terreno propício para ser pensada como a arte de experiências compartilhadas. A circunscrição dessa experiência se deve também a uma busca pela inclusão dos processos de subjetivação e significação no círculo epistemológico em que a instância do sensível é intermediada pelo outro. Erika Fischer-Lichte demonstra como o poder da performance desestabiliza princípios secularmente instaurados, justamente por se concentrar entre as polarizações, considerando a experiência como seu escopo originário:

The central concern of the performance was not to understand but to experience it and to cope with these experiences, which could not be supplanted there and then by reflection. In this way, the performance redefined two relationships of fundamental importance to hermeneutic as well as semiotic aesthetics: first, the relationship between subject and object, observer and observed, spectator and actor; second, the relationship between the materiality and the semioticity of the performance's elements, between signifier and signified. (FISCHER, 2008, p. 17) ${ }^{4}$

\footnotetext{
4 "A preocupação central da performance não é entender, mas experimentar e lidar com essas experiências, que não poderiam ser suplantadas aqui e ali por reflexão. Nesse sentido, a performance redefiniu duas relações de fundamental importância para as estéticas hermenêutica e semiótica: em primeiro lugar, a relação entre sujeito e objeto, observador e observado, espectador e ator; em segundo lugar, a relação entre a materialidade e a semioticidade dos elementos da performance, entre significante e significado." (Tradução nossa).
} 
Na obra O poder transformador da Performance (2008), Erika Fischer-Lichte esclarece vários pontos artísticos e contextuais que remetem ao início dos anos 60, como o momento em que a arte ocidental experimenta propostas de caráter performativo, ou mesmo participa do que a autora define como "performative turn", espécie de virada performativa que agrega as mais diferentes artes junto a um sentimento de ruptura com os gêneros e as fronteiras estabelecidas.

Fischer chega a propor uma estética do performativo com base em sua investigação sobre a necessidade de instrumentos teóricos capazes de abranger determinadas expressões que não cabem mais na estética tradicional. Ao colocar a dimensão performativa do teatro como prática cultural e aproximar o terreno teatral dos paradigmas da performance, abre-se uma conjuntura em torno dos processos geradores. Os desdobramentos ou reflexos da performance no universo teatral terão impacto, principalmente, no âmbito da pluralidade dos processos, eixo dos preceitos performáticos que desestabilizam as regras dos discursos hegemônicos. Ao compartilhar o espaço laboral, a performance contrapõe a supremacia do encenador e intensifica a rede de transformações vividas nesse período histórico de transições.

A performance tem um significado especial para o pensamento sobre o novo papel do dramaturgo, uma vez que, juntamente com seus pressupostos, evoca inúmeras questões envolvendo o labor, o fazer e a constituição da obra. É justamente nesse ponto que novas formas de se compor dramaturgicamente são experienciadas, além do campo expandido originário que possibilita o viés autônomo e heterodoxo que essa abrangência conceitual pode ressignificar.

Pensar a dramaturgia como o resultado de experiências vivenciadas na gênese criativa proporciona um espaço transgressor e por si só multifônico, no sentido de agregar no mesmo ato (seja no acontecimento das temporadas ou na sua vivência) uma rede propositiva de distintos segmentos que se atravessam na partilha que constitui a carpintaria da cena. $\mathrm{O}$ teatro feito em grupo expande as fronteiras dessa experiência partilhada, desde sua projeção até o encontro com o público, onde de fato ela se concretiza. Nesse sentido, a dramaturgia aparece como objeto e instrumento de mediação do repertório criativo experienciado, expondo os abismos do eu e do outro que se dilatam na lida dos ensaios com o objetivo de buscar o acabamento satisfatório capaz de identificar determinado coletivo junto ao projeto que idealiza.

Esse deslocamento envolvendo o conceito de experiência junto ao espaço processual torna-se fundamental para redefinir o ofício dramatúrgico a partir das instâncias que passam a integrar sua atuação. $O$ fato é que, até então, o conceito de experiência sempre esteve próximo das prerrogativas inerentes ao fenômeno do acontecimento, encontro para o qual se prevê o público. No entanto, a noção de experiência, de colocar-se em experiência, também abrange o fazer teatral em sua gênese, em seus modos de concepção e tessitura. A premissa do "experienciar" reúne, no processo de criação teatral, os artistas participantes que projetam coletivamente o ato do compartilhamento. Esse espaço fundante entrecruza saberes, dúvidas e provoc(ações), em uma rede complexa que tem como alicerce o encontro dos artistas envolvidos que se colocam como agentes e objetos dessa experiência processual.

A dramaturgia contemporânea, quando pensada sob o viés da experiência, ressignifica o próprio ato de se constituir, sinalizando que o processo pode caminhar para o performático, a partir do momento em que essa experiência é também conduzida ou provocada pelo dramaturgo. Os processos coletivos de experienciação dramatúrgica atuais, reflexos das criações coletivas e, posteriormente, dos processos colaborativos, edificam um espaço propulsor para o encontro de artistas com o mesmo intuito laboral. Se antes a primazia textocêntrica simplificou o corpus artístico e o advento do encenador homogenizou suas parcerias, hoje, o espaço da experiência da artesania teatral (atento à autonomia das linguagens e a não hierarquização das funções) constitui um status diferenciado, no qual cada artista imprime suas singularidades e especificidades (os processos colaborativos dos anos 90 atestam isso). O viés performático de atuação dramatúrgica surge, então, do reconhe- 
cimento desse espaço em que todos os envolvidos têm como horizonte o fato de que o resultado desse encontro (obra acabada ou não) será o que se constrói das relações tecidas nele, e cada integrante contribui com parcelas e materiais distintos, cabendo ao dramaturgo o olhar e a articulação arquitextual que interpassam o plano político, estético, social e cultural dessa genealogia (prerrogativa dos princípios processuais da performance). Assim, dramaturgia passa a ter um significado que integra a participação de cada um ao referencial de pertencimento à esse espaço, à esse encontro, à experiência do criar com e a partir do outro.

Nessa vertente, chamamos atenção para a redefinição que o papel do dramaturgo assume. Este passa a ter a responsabilidade (e não a preponderância) de explorar, provocar e reunir estruturas de suporte para a obra, fruto de uma rede corporativa que se retroalimenta nas instâncias do sensível, do artístico e do social. A estrutura, e não somente o texto (independente dos formatos que este adquire), também tem um significado autoral, coletivo por excelência, e específico na forma com que foi composto. $\mathrm{O}$ dramaturgo passa a se encarregar (e não somente ele) de testar, ampliar, desconstruir, confrontar e efetivar essas dimensões a partir da sua intervenção nos diferentes espaços, vínculos $\mathrm{e}$ domínios.

Estes espaços de experiência conferem à prática dramatúrgica o status propulsor dessa dinâmica, dessa rede onde singularidades, subjetividades, linhas de pensamento, habilitações técnicas e particularidades artísticas, que passam a eleger a alteridade como requisito para o prospecto polifônico e pluridimensional que a práxis fundamenta. Articular o pensamento dramatúrgico com o conceito de experiência significa entender o dramaturgo como o profissional que propulsiona o entrecruzamento dos olhares e dos pensamentos dos envolvidos no processo, aquele que proporciona zonas de tensão entre as certezas e as dúvidas, que trabalha com a materialização da obra estando aberto à experiência do "criar", a qual também inclui intuições, o acaso, recortes, escolhas, convergências e divergências. Nada se descarta, mas nem tudo fica. Todos os agentes da criação teatral podem exercer o papel de motor da experimentação, mas ao dramaturgo cabe recolher os indícios mais reveladores dessa vivência, escrituralmente levantada em formato dramatúrgico.

A dramaturgia, quando estruturada sob os pilares que fundamentam essa partilha, passa a ser construída pelas ressonâncias que do coletivo se desdobram: os ganhos, as perdas, as tensões e as descobertas provenientes dos ensaios. O dramaturgo imprime sua forma de concepção e evidências nessa rede sensível colocada em jogo (assim como os outros agentes criadores), junto à diversidade de formas de composição que lhe cabe equacionar como instância identitária das vivências. O reflexo que as práticas dramatúrgicas (junto ao viés coletivo e seus respectivos desdobramentos) imprimem na produção dos últimos decênios é fruto desse espaço questionador de modelos e paradigmas, resgatando o princípio coletivista, base da arte teatral.

A partir do momento em que os grupos pluralizam suas formas de elaboração dramatúrgica (coletivas, colaborativas ou compartilhadas), os dramaturgos também ampliam o seu olhar sobre o diálogo criacional em torno da tessitura conjunta. O resultado dessa nova expectativa apresenta uma diversidade de dramaturgias que esfacelam os princípios representativos, exploram outras possibilidades de se relacionarem com o público e investigam outras fontes e dispositivos escriturais. Essa expectativa é que permite a variação de micropoéticas extensivas que, ao confrontar a fixidez de modelos e processos, constrói estruturas e tessituras com um viés crítico em relação ao próprio espaço contemporâneo no qual estão inseridas, também expondo as novas micropolíticas de atuação, responsáveis diretas por essa diversidade.

Dessa forma, a dramaturgia, pensada a partir do conceito de experiência, redimensiona o papel do dramaturgo, que passa a articular, provocar e dinamizar o espaço destinado à experimentação de poéticas coletivas, cuja reconfiguração é sensível às novas incorporações que a prática contextualiza. Além disso, o dramatur- 
go também amplia o olhar sobre o próprio ofício e sobre o outro, do qual todo processo parte.

Nessa conjuntura, o dramaturgo é responsável pela escrita dramatúrgica (textual, espetacular, performática), na qual recai o objetivo de estarem presentes as vozes e os modos de compor de todos os agentes da criação, o que, consequentemente, torna a escrita permeável ao princípio heterogêneo à sua gênese. Dessa forma, entendemos dramaturgia como um conceito expandido, colocando o dramaturgo como agente fronteiriço nas artes da cena, tornando-o corresponsável pela manutenção da identidade estrutural do coletivo onde habitam suas vozes constitutivas, sendo, inclusive, impelido a se posicionar perante o contexto emergente e as formas escolhidas para teatralizá-lo. Não se trata apenas da assinatura da obra, mas de imprimir nessa assinatura (coletiva por escolha) a instância política, ideológica e estética vivenciada junto ao coletivo, competência que expande sua funcionalidade para uma frente performática de atuação e inserção.

A dramaturgia passa a ser entendida como um instrumento capaz de expor uma escrita oriunda de um terreno compartilhável e plural, no qual as especificidades estão presentes dentro das microesferas internas e externas que a compõem, sendo que o todo ratifica o viés coletivo de sua gênese. O dramaturgo encerra sua antiga suposição individualizada, por vezes debruçada sobre o único vetor de responsabilidade (o texto, enquanto palavra), passando a atuar, como performer, na tensão entre fronteiras e domínios, no questionamento de modelos institucionalizados e na dinamização dos processos que tornam possível o encontro do coletivo com ele mesmo e, também, com o público.

Ao reconhecer a dramaturgia como um espaço no qual experiências são vividas e tecidas não se propõe apenas uma imersão estética nas obras resultantes desse processo, mas um diálogo com todas as instâncias que são mobilizadas dentro desse referencial. Os princípios de trabalho que se atêm à dramaturgia como uma escrita sensível à rede de saberes e aberta a esse repertório ratificam o entendimento plural da tessitura do texto teatral, em particular nas obras contemporâneas, na quais o viés performático se torna mais evidente.

O valor simbólico do papel do dramaturgo na prática de estruturação do material criado e de suas tessituras possíveis (a partir dos elementos convergentes e divergentes que agrega) também redimensiona os arredores do ofício. Ao nos referirmos à dramaturgia como o espaço resultante de uma experiência coletiva e, também, como uma estrutura macro que, em sua gênese, reflete uma série de micro-escolhas correspondentes aos planos estético, subjetivo e processual, modificamos o olhar em relação ao seu profissional responsável, principalmente na cena contemporânea emergente, que destaca obras e processos em igualdade de importância, já que um acaba se tornando parte do outro.

$\mathrm{Na}$ frente performática de atuação dramatúrgica, os princípios lógicos que sustentam o eixo dramático perdem força diante de uma tessitura constituída processualmente, e diante da materialidade de fontes originárias que se ampliam em torno de uma válvula motora que é dramatúrgica e não textual. A reconfiguração pautada nessa frente de trabalho, ou mesmo na ideia do performer como uma apropriação conceitual, deriva da necessidade de permear o trânsito funcional que o campo expandido em torno da dramaturgia adquire, aproximando-o do viés composicional performático, além de reconhecer o valor simbólico que a dramaturgia promove, principalmente quando a textualidade que se persegue é entendida como o resultado de uma experiência vivida, e o dramaturgo passa a ser corresponsável pelas mediações e interfaces dessa experiência. 


\section{REFERÊNCIAS}

CARLSON, Marvin. Performance: uma introdução crítica. Belo Horizonte: Editora da UFMG, 2009. $284 \mathrm{p}$.

COHEN, Renato. Performance como linguagem. São Paulo: Perspectiva, 1989. $176 \mathrm{p}$.

COHEN, Renato. Work in progress na cena contemporânea: criação, encenação e recepção. São Paulo: Perspectiva, 2004. 135 p.

FÉRAL, Josette. Além dos limites: teoria e prática do teatro. São Paulo: Perspectiva, 2015. $424 \mathrm{p}$.

FISCHER-LICHTE, Erika. The transformative power of performance. New York: Routledge, 2008. 242 p.

PAIS. Ana. O Discurso da Cumplicidade: dramaturgias contemporâneas. Lisboa: Colibri, 2004. 119 p.

PAIS, Ana. "O crime não compensa ou o poder da dramaturgia". In: Temas para a dança brasileira. [Org. Sigrid Nora]. São Paulo: Edições SESC/SP, 2010. 344p.

PEDRON, Denise. Um olhar sobre a performatividade na cultura contemporânea: a performance como conceito e a produção artística de Diamela Eltit. 2006. 172 f. Tese (Doutorado em Estudos Literários) - Universidade Federal de Minas Gerais, Faculdade de Letras, Belo Horizonte/MG.

SCHECHNER, Richard. Performance theory. Routledge: London and New York, 1988. 320 p.

SCHECHNER, Richard. O que é performance?. O Percevejo: Revista de Teatro, Crítica e Estética. Ano 11, no 12. NEPPA/Unirio: Rio de Janeiro, 2003.

SCHECHNER, Richard. "O que é performance?" In: Performance studies: an introduction. New York \& London: Routledge, 2006. P. 28-51. 333 p. 


\begin{abstract}
This article analyzes the approximation of the fields of dramaturgy and performance, mobilizing notes around the territories and the borders of their epistemological and procedural bases. The theoretical discussion starts with Richard Schechner, Erika Fischer-Lichte, Renato Cohen, Denise Pedron and Ana Pais, focusing on the investigation of how the consequences of the performance's principles contaminate the thought and praxis of writing for the stage. In this perspective, we discuss the re-dimensioning of the playwright's work and its symbolic role in the creative genesis, especially when his performance incorporates a performance front and dramaturgy becomes understood as an expanded field.
\end{abstract}

\title{
Keywords
}

Looping: Dramaturgy; Performance; Expanded field.

\section{Resumen}

Este artículo analiza la aproximación de los campos de la dramaturgia y de la performance, movilizando apuntes alrededor de los territorios y de las fronteras de sus bases epistemológicas y procesales. La discusión teórica parte de Richard Schechner, Erika Fischer-Lichte, Renato Cohen, Denise Pedron y Ana Pais, con foco en la investigación sobre cómo los desdoblamientos de los principios de la performance contaminan el pensamiento y la praxis de la escritura al escenario. En esta perspectiva, se discute el redimensionamiento del trabajo del dramaturgo y su papel simbólico en la génesis creativa, principalmente cuando su actuación incorpora un frente performático y la dramaturgia pasa a ser entendida como campo expandido.

\section{Palabras clave}

Looping: Dramaturgia; Performance; Campo ampliado. 